\title{
The Effectiveness of Entomopathogenic Fungi Beauveria bassiana with the Addition of Insect Growth Regulator Lufenuron for Controlling Bactrocera carambolae
}

\author{
Mochammad Syamsul Hadi ${ }^{*}$, Toto Himawan ${ }^{2}$, Luqman Qurata Aini² \\ ${ }^{1}$ Graduate Program Plant Science Faculty of Agriculture, Brawijaya University \\ ${ }^{2}$ Department of Plant Protection Faculty of Agriculture, Brawijaya University
}

\begin{abstract}
The study of the effectiveness of entomopathogenic fungus Beauveria bassiana (Bals) Vuill. with the addition of an insect growth regulator (IGR) lufenuron to control the fruit fly Bactrocera carambolae (Drew and Hancock) (Diptera: Tephritidae) was conducted at the Laboratory of Toxicology and Laboratory of Entomology, Department of Plant Pests and Diseases, Faculty of Agriculture, University of Brawijaya Malang from March 2012 until December 2012. This study examined the effect of lufenuron to the development and sporulation of $B$. bassiana and the effectiveness of the fungus B. bassiana in combination with several concentrations of lufenuron $(0.5,1,1.5 \mathrm{~mL} / \mathrm{L})$ on the mortality of fruit fly larva $B$. carambolae. The results showed that the addition of lufenuron at the concentration of $1 \mathrm{~mL} / \mathrm{L}$ could significantly increase the sporulation of B. bassiana. The addition of B. bassiana at $108 \mathrm{spores} / \mathrm{mL}$ combined with lufenuron at the concentration of $1 \mathrm{~mL} / \mathrm{L}$ applied to compost pupation medium of larva of $B$. carambolae is significantly able to suppress the formation of the fruit fly pupa and imago of B. carambolae.
\end{abstract}

Keywords: Beauveria bassiana, Bactrocera carambolae, Effectiveness.

\section{INTRODUCTION}

The fruit fly is one of the most harmful pests which affects both the quantity and quality of fruits and vegetables. This pest is a key pest on fruit all over the world, including in Indonesia [1]. The genus of Bactrocera has various types of destructive fruit flies in Indonesia, one of them is Bactrocera carambolae, Drew and Hancock (Diptera: Tephritidae).

B. carambolae is one of 52 species in the complex group $B$. dorsalis (Hendel) and could attack a wide range of fruits including papaya and starfruit. This fly has reportedly attacked $75 \%$ of fruit trees and is the second most major pest of fruit crops afer B. papaye [2]. Demage caused by

\footnotetext{
"Corresponding author:

Mochammad Syamsul Hadi

Graduate Program Plant Science Faculty of Agriculture,

Brawijaya University

E-mail: sam_11215@yahoo.com
}

B. carambolae is usually seen from the puncture marks found on the skin of fruit. Ovipositor punctures by $B$. carambolae females are easily recognized by discoloration of the fruit skin around the puncture marks and the fruit will decay quickly.

The damage caused by $B$. carambolae fruit flies can be prevented and reduced by control efforts. The control measure for fruit flies can be done either by physical, chemical, or biological methods. The control of fruit flies was commonly done by using chemical insecticides. However, the use the insecticides causes a lot of problems such as the increasing of resistance, environmental pollution, poisoning, and death of non-target animals.

An alternative control of the $B$. carambolae fruit fly could be done by using natural enemies either of parasitoids, predators, or microbial pathogens. The most vulnerable life stage of fruit flies, which is frequently attacked by natural enemies, is at the stage of final instar of larva, pupa, and 
imago. Eggs and early instar of larva tend to be protected from the attack of natural enemies because they exist in the fruits. However, the eggs and early instar of larva could also be attacked by parasitoids, mites, and pathogenic microorganisms [3]. The control of eggs and early instar of larva of $B$. carambolae will be more effective because it can prevent the formation of pupa and imago which leads to reducing the spread rate of $B$. carambolae.

The control of early instar of larva from B. carambolae using pathogenic microorganisms is considered more effective because it is environmentally friendly and does not cause resistance. One of pathogenic microorganisms that can be used to control the larva $B$. carambolae is the fungus Beauveria bassiana (Bals) Vuill. This fungus has been widely used in various types of pest control on a wide range of plant species. B. bassiana has been proven to be effective in controlling a variety of pests. However, when it is applied in the field, the pathogenicity is not consistent due to the influence of unfavorable environmental conditions, especially temperature, humidity, and solar radiation [4]. To increase the pathogenicity of $B$. bassiana, the formulation of isolates as well as adding a carrier that can improve the performance of the fungus must be done. One compatible carrier that can increase the pathogenicity of B. bassiana is the addition of Insect Growth Regulator (IGR) [5].

IGR is an insecticide belonging to the new group that has high selectivity towards the target insect that is in accordance with the principles of integrated pest management (IPM). IGR can interfere or inhibit the life cycle of pests, hence the pests cannot reach adulthood, and are not able to reproduce. One of the insecticides included in the IGR is lufenuron. Lufenuron works by inhibiting the synthesis of chitin for the skin replacement process. In addition to inhi-biting the synthesis of chitin, lufenuron also in-terferes in the reproductive system of target insect pests [7]. The combination of $B$. bassiana with the addition of IGR is expected to be a new approach for enhancing the effective control of B. carambolae.

Table 1. Sporulation Test B. bassiana with the addition of Lufenuron on different concentrations.

\begin{tabular}{|ccc|}
\hline Treatment & $\begin{array}{c}\text { B. bassiana } \\
(\text { spore } / \mathrm{ml})\end{array}$ & $\begin{array}{c}\text { Lufenuron } \\
(\mathrm{ml} / \mathrm{l})\end{array}$ \\
\hline P1 & $10^{8}$ & 0,5 \\
P2 & $10^{8}$ & 1 \\
P3 & $10^{8}$ & 1,5 \\
Control & 0 & 0 \\
\hline
\end{tabular}

\section{MATERIALS AND METHODS}

\section{The effect of the addition of Lufenuron on the Sporulation of B. bassiana}

The experiments were conducted using a completely randomized design (CRD) with four treatments (Table 1) and three replications. B. bassiana (final spore density of 108 spores/mL) was mixed in potato dextrose broth in a $125 \mathrm{~mL}$ Erlenmeyer flask. Lufenuron with a final concentration of $0.5,1$, and $1.5 \mathrm{~mL} / \mathrm{L}$ was then mixed in the medium and then shaken in a rotary incubator with a speed of $120 \mathrm{rpm}$. Development of fungal sporulation of $B$. bassiana was observed every 3 hours until the sporulation reached a maximum.

\section{Treatment on Larvae of $B$. carambolae by the addition of $B$. bassiana and Lufenu- ron on Pupation Compost Media}

Eggs of B. carambolae have been collected and harvested on the same day and artificial feed was added, which was distributed evenly over plastic trays $(22 \mathrm{~cm}$ long, $17 \mathrm{~cm}$ wide, and $5 \mathrm{~cm}$ high). After the eggs hatch, the larva of $B$. carambolae will feed the artificial feed medium, which con-sists of a mixture of wheat bran, yeast, sugar, so-dium benzoate and nipagen. When larva of $B$. carambolae reached third instar (aged 7-8 days), they were 
ready to become pupa and they will come out of the feed medium and jump into the pupation media. A hundred third instar larva were collected and put on the petri dish con-taining the artificial feed. Then the petri dish was put on a plastic tray containing pupation media (a mixture of sawdust + compost with a ratio of $2: 1=\mathrm{w} / \mathrm{w}$ ) that has been mized with a combination of $B$. bassianaand lufenuron with different concentrations (Figure 1 and Table 2). After 7 days, the pupa was separated from the pupation media by sieving. Pupa of $B$. carambolae, which has been separated from the pupation media, were then observed for their development.

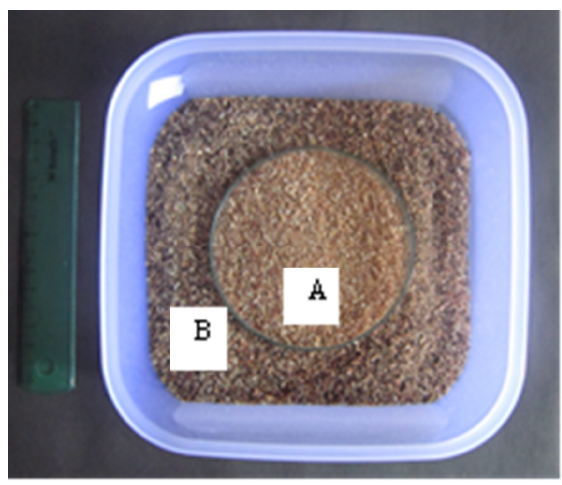

Figure 1. Treatment of Larva of B. carambolae on Compost Pupation Media $A=$ Artificial feed for larva of B. caramboale, $\mathrm{B}=$ Compost Pupation Media

Table 2. Treatment of B. bassiana and Lufenuron on compost pupation media

\begin{tabular}{|ccc|}
\hline Treatment & $\begin{array}{c}\text { B. bassiana } \\
\text { (spore/ml) }\end{array}$ & $\begin{array}{c}\text { Lufenuron } \\
(\mathrm{ml} / \mathrm{l})\end{array}$ \\
\hline P1 & $10^{8}$ & 0,5 \\
P2 & $10^{8}$ & 1 \\
P3 & $10^{8}$ & 1,5 \\
Control & 0 & 0 \\
\hline
\end{tabular}

\section{RESULTS AND DISCUSSION}

\section{The Effect of the Addition of Lufenuron to Fungal Sporulation of B. bassiana}

The results showed that the addition of lufenuron affected the development of B. bassiana sporulation (Figure 2). The development of fungal sporulation of B. bassiana was observed every 3 hours until sporulation reached the maximum point. The development of sporulation $B$. bassiana with the addition of lufenuron can be seen in Figure 2.

Figure 2 shows that sporulation of B. bassiana with the addition of lufenuron concentration of $1 \mathrm{~mL} / \mathrm{L}$ (P2) reached the highest density and was significantly different compared with those of other three treatments. The sporulation of B. bassiana on $\mathrm{P} 3$ (B. bassiana + lufenuron $1.5 \mathrm{~mL} / \mathrm{L}$ ) as well as on P2 (B. bassiana + lufenuron $1 \mathrm{~mL} / \mathrm{L}$ ) were significantly increased at the observations of 15-45 hours, when compared with controls. The addition of lufenuron at $0.5 \mathrm{~mL} / \mathrm{L}$ did not have a significant difference on the sporulation of $B$. bassiana compared with that of the control.

Based on the result above, it can be suggested that the combination of fungus B. bassiana with lufenuron was compatible when applied together. This result is similar to the work of [7], which reported the compatibility of the addition of lufenuron in fungus $M$. anisopliae. Sporulation rate 
of B. bassiana on P2 and P3 was also higher than those on P1 and controls (Figure 6) indicated that the addition of lufenu-ron at the concentration of 1 and $1.5 \mathrm{~mL} / \mathrm{L}$ could increase the rate of $B$. bassiana sporulation. This result is similar to the study conducted by [7], which reported that the addition of lufenuron.

At the concentration of $1 \mathrm{~mL} / \mathrm{L}$ may increase the rate of sporulation of entomopathogenic fungus Metrhizium anisopliae. However,

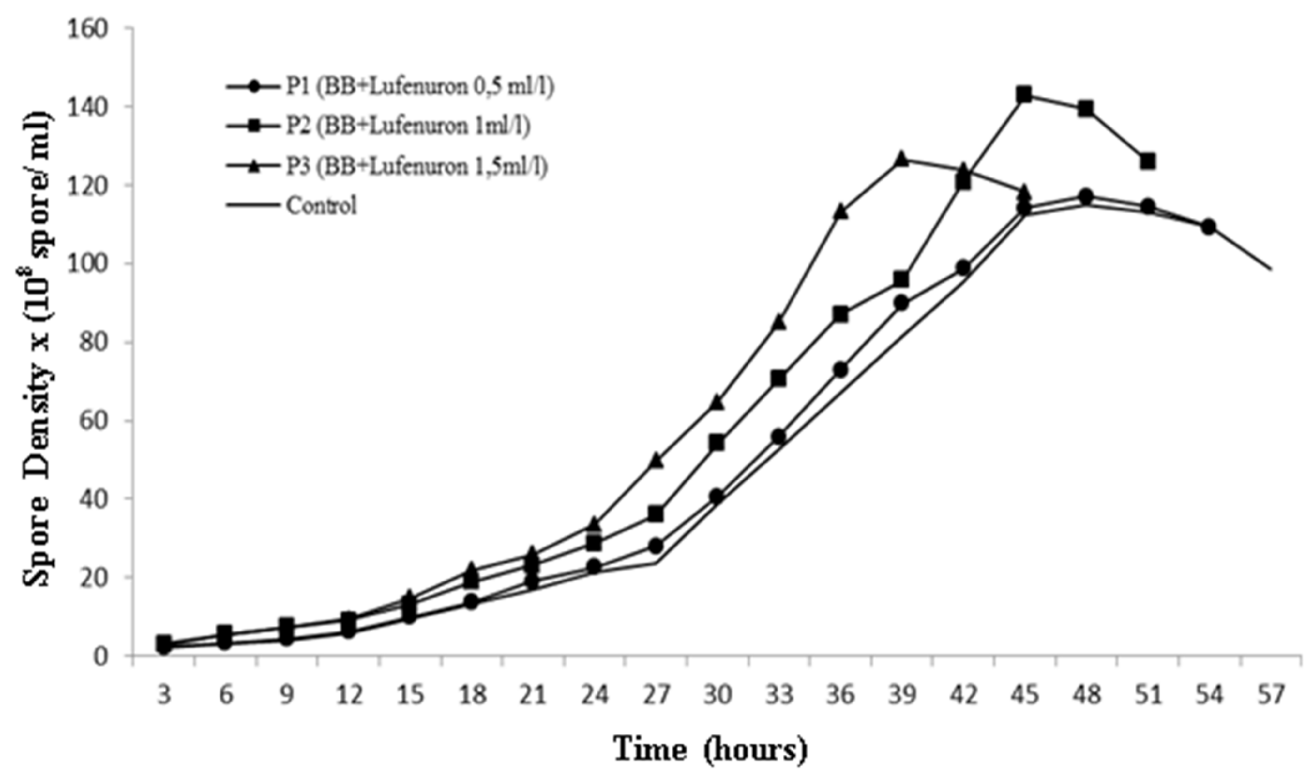

Figure 2. Graph of sporulation of fungi B. bassiana

Table 3. The Percentage of Pupa and Imago of B. carambolae Formed from larvae laid on compost pupation media treated with B. bassiana and Lufenuron

\begin{tabular}{|c|c|c|}
\hline Treatment & $\begin{array}{c}\text { Larva become pupa } \\
(\%)\end{array}$ & $\begin{array}{c}\text { Pupa become adult } \\
(\%)\end{array}$ \\
\hline P1 (BB + Lufenuron $0,5 \mathrm{ml} / \mathrm{l})$ & $85,33 \mathrm{~b}$ & $81,33 \mathrm{~b}$ \\
\hline P2 (BB + Lufenuron $1 \mathrm{ml} / \mathrm{l})$ & $64,33 \mathrm{ab}$ & $54,67 \mathrm{a}$ \\
\hline P3 (BB + Lufenuron $1,5 \mathrm{ml} / \mathrm{l})$ & $71,67 \mathrm{ab}$ & $64,33 \mathrm{ab}$ \\
\hline Kontrol (Tanpa BB + Lufenuron) & $100,00 \mathrm{~b}$ & $100,00 \mathrm{c}$ \\
\hline
\end{tabular}

Note: Numbers followed by same letters are not significantly different in DMRT test at $\mathrm{p}<0,05$.

mechanism underlying the cause of increasing sporulation rate of $M$. anisopliae sporulation is still unknown

Treatment on Larvae of $B$. carambolae by the addition of $B$. bassiana and Lufenuron on Pupation Compost Media

The result showed that the addition of B. bassiana and lufenuron with a concentration of $1 \mathrm{~mL} / \mathrm{L}$ treatment revealed the lowest number of imago formation compared with those of other treatments, although the number of pupa formed was not significantly different for all treatments (Table 3).

This result suggests that the application of $B$. bassiana and lufenuron at a con-centration of $1 \mathrm{~mL} / \mathrm{L}$ in the compost pupation media of $B$. carambolae was effective in suppres-sing the formation of the imago B. carambolae.

Larvae of $B$. carambolae infected with $B$. bassiana and lufenuron that still survived could reach the stadia of pupa and imago, but the formed 
pupa have abnormalities or the size is smaller than the normal pupa of B. carambolae (Figure 3).

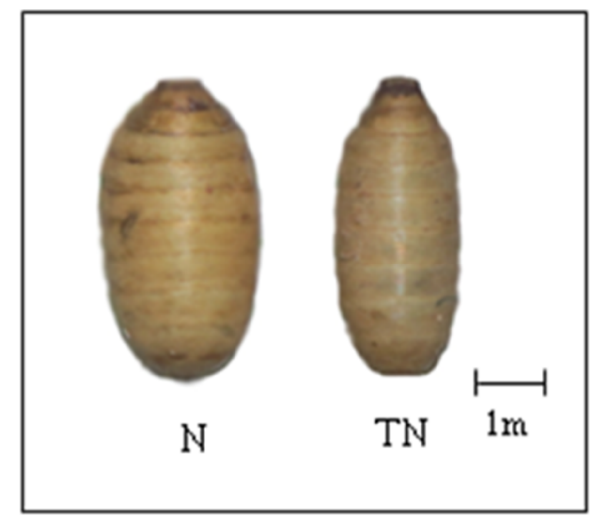

Figure 3. The difference of B. carambolae pupa after treatment of $\mathrm{B}$. bassiana and lufenuron; $\mathrm{N}=$ normal Pupa, $\mathrm{TN}=$ abnormal pupa

The abnormalities of pupa may be due to the infection B. bassiana and lufenuron which occurs in larval stadia. It has been reported that B. bas-

\section{CONCLUSION}

The application of $B$. bassiana combined with lufenuron are compatible when applied together; it can even increase the sporulation rate. The application of $B$. bassiana combined with lufenuron is significantly effective in controlling the pest fruit fly B. carambolae. Thus, it has the potential to be used as a combination for the environmental friendly control of the fruit fly B. carambolae.

\section{REFERENCES}

1. Kuswadi AN, Darmawi, Indarwatmi M(1997) Biologi Lalat Buah Bactrocra carambolae dalam Biakan di Laboratorium dengan Makanan Buatan.Seminar Nasional. Biologi XV.PEI dan Univer-sitas Lampung. Bandar Lampung. 15101514.

2. Rachmawati R (2006) Pengaruh Ekstrak Biji Nimba (Azadiracta indica (A. Juss)) pada Pola Perkembangan dan Pola Protein Lalat Buah Bactrocera carambolae Drew dan Hancock (Diptera: Tephritidae). Tesis. Program Studi Ilmu Tanaman. Universitas Brawijaya. Malang: 61.

3. Artayasa IP (1999) Potensi Parasitoid Dalam Pengendalian Lalat Buah (Bactrocera carambolae) siana can produce several toxins such as beauvericin, beauverolit, isoralit, and oxalic acid which can cause blood clots and cessation of blood circulation in insects. B. bassiana is also capable of mechanically damaging the haemocoel network, such as the gastrointestinal tract, muscles, ner-vous system, and respiratory system [8]. All these processes can affect the growth and development of insects, can cause paralysis and can even cause death in infected insects.

In addition, lufenuron is also a chitin synthesis inhibitor. According to [9], chitin is a major component of insect exoskeletons. Disruption of the process of formation of larval chitin cannot resume the normal growth and development. The growth of insects on young growth phase (larvae) are controlled by juvenile hormones produced in the brain. Juvenile hormones regulate when the larval phase ends, which is then followed by molting into adults. Lufenuron is able to work like juvenile hormone, which can interfere the larval growth.

Drew \& Hancock di Kebun Percobaan BuahBuahan Subang, Jawa Barat. Tesis Magister Program Studi Biologi, Pasca Sarjana ITB. Bandung.

4. Inglis GD, Goettel MS, Johnson DL (1995) Influence of ultraviolet light protectants on persistense of the entomopathogenic fungus Beauveria bassiana. Biol Contr 5: 581-590.

5. Krysan JL, John D, (2010) Insect Growth Regultors. The Fruit Research and Extension Center Orchard Pest Management. http:// jenny.tfrec.wsu.edu/opm/displayIPMp60.

Accessed date 18 Pebruary 2010

6. Hoffman KH, Lorenz MW (1998) Recent Advances in Hormones in Insect Pest Control. Phytoparasitica 26:4. http://www.beyond pestici des.org/infoservices/ pesticidefactsheets/ toxic/ insectgrowthregulators.htm. Accessed date 18 Pebruary 2010.

7. Alves MMTA, Orlandelli RC, Lourenco DAL, Pamphile JA (2011) Toxicity of the Insect Growth Regulator Lufenuron on the Entomopathogenic Fungus Metarbizium anisopliae (Metsch nikoff) Sorokin Assessed by Conidia Germination Speed Parameter. African Journal of Biotechnology. 10(47): 9661-9667.

8. Robert DW and Yendol MG (1982) Use of Fungi For Microbial Control of Insect: 125 - 145. dalam 
Burger HD and Hussey NW (eds) (1982)

Microbial Control of Insect, Mites. Academic

Press London. New York.
9. Tunaz H, and Uygun N (2004) Insect Growth Regulators for Insect Pest Control. Turk. J. Agri. 28: 377-387. 